\title{
Correlation of body mass index on waist circumference and blood pressure
}

\author{
Yoni Astuti ${ }^{1}$, Ikhlas Muhammad Jenie ${ }^{2}$ \\ ${ }^{1}$ Department of Biochemistry, Faculty of Medicine and Health Sciences, Universitas Muhammadiyah Yogyakarta, \\ Indonesia \\ ${ }^{2}$ Department of Physiology, Faculty of Medicine and Health Sciences, Universitas Muhammadiyah Yogyakarta, \\ Indonesia
}

\begin{abstract}
Article Info
Article history:

Received Mar 27, 2020

Revised Jul 23, 2020

Accepted Sep 15, 2020

\section{Keywords:}

BMI

Elderly

Waist circumference

ABSTRACT

The increasing number of elderly on these recent days demands an improved quality of health for the elderly. Independence of the elderly is important in order to be happy and not to be a burden on their families. Health monitoring continuously is an effort to prevent disruption on the health conditions of the elderly. The health status of elderly people is important to know to follow up on prevention programs for the emergence of certain diseases in the elderly. This study aims to look for potential health problems for elderly people in Gamping, Sleman, DIY, Indonesia. The method of this research was cross sectional analysis using secondary data. Sample collection is consecutive subjects. Subjects were 158 people with a mean age of men $(67.8 \pm 7.1)$ years while women were $67.5 \pm 7.3$ years. The data was analyzed using the bivariate correlation test with CI 99\%. The results of the analysis showed that the average body mass index with an average waist circumference was positively correlated $(r=0.66 ; p: 0.000)$, but did not correlate with systole pressure $(\mathrm{r}=-0.009 ; \mathrm{p}=0.97)$ diastole $(\mathrm{r}=0.093 ; \mathrm{p}=0.477)$, age $(-0.05 ; \mathrm{p}=0.71)$, and gender $(\mathrm{r}=-0.146 ; \mathrm{p}=0.27)$. The potential health problems among the elderly is the risk of high BMI due to the larger waist circumference
\end{abstract}

This is an open access article under the CC BY-SA license.

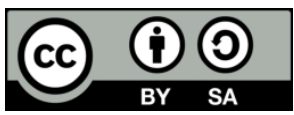

\section{Corresponding Author:}

Yoni Astuti,

Department of Biochemistry,

Faculty of Medical and Health Sciences, Universitas Muhammadiyah Yogyakarta,

Jl. Brawijaya, Tamantirto, Kasihan, Bantul, DI Yogyakarta 55381, Indonesia.

Email: yonia@umy.ac.id

\section{INTRODUCTION}

The elderly population was increasing yearly recently, due to better medical founding on our life. The increasing of life expectancy was one of the effects of good quality health also. WHO reported that population with age $\geq 65$ years old is projected grow from around 524 million in 2010 to around 1.5 billion with the most increasing in developing countries [1]. Indonesia has a policy on the handling of the elderly by including it in the Elderly welfare law No.13 of 1998. The law defines the elderly as someone who has reached the age of 60 years and over, men and women, still able to do work and or activities that can produce goods and or services or are powerless to make a living so that their lives depend on others [2]. The health condition of the elderly should be aware of day to day considering the aging condition of the body system at risk of deterioration, such as organ physiological function, immunity system, psychiatric and others. The decline of the physiological system allows the emergence of various risks of diseases such as hypertension, hyperglycemia, and allergies. This risk is strongly associated with previous individual life 
habits. person's life habits are much influenced by genetic factors and environmental factors such as local culture that influence eating habits, behavior etc. Daerah Istimewa Yogyakarta (DIY) is a province that has the highest life expectancy in Indonesia, which is around 74.74 while the average in Indonesia is 71.06 years. DIY has a population with $\geq 51$ years of age estimated at 927,115 people [3]. Sleman, one of DIY districts has the highest life expectancy in DIY. Indonesian government's efforts in maintaining the health of the elderly is realized with the program of Posyandu (integrated health service post). Elderly Posyandu activities carried out so far has been routine. Elderly health examination results so far reported to the higher unit, namely Primary Health care System, as the Elderly posyadu "Melati Patukan Ambarketawang Gamping Sleman". However, the progress on the elderly health in the Patukan have not been analyzed so far. Analysis of routine elderly health needed to find out as early as possible the possible risk factors that occur. Considering each area will have the potential risk of different diseases that will require promotion and preventive efforts differently. Therefore, it is important to carry out a routine health examination analysis for the elderly at an average annual rate. These results can be used as a basis for mapping the predicted risks that will occur, so prevention efforts can be prepared. The most health problems in Indonesian elderly were hypertension, arthritis, stroke, chronic obstructive pulmonary disease (COPD), diabetes mellitus, and cancer [4]. Hypertension due the blood pressure level more then 140-159 systole and diastole 90-99 as hypertension stage 1 . Meanwhile 160 or more for systole and diastole 100 or more as hypertension stage 2 [5]. This study was conducted to reveal the correlation of body mass index on waist circumference and Blood Pressure

\section{RESEARCH METHOD}

This research was cross sectional research with data in January to December 2017-2019. Data was collecting from Posyandu Lansia Amabarketawang Gamping Sleman. The number of subject that has complete information was 158 people which were 130 female and 28 male. Data information about age, occupies, education level, Body weight and high, waist circumference, Systole and diastole, was analyzed with correlation analyzing. Data about activity, smoking, low fiber menu and alcohol consume was collecting by interview. This research has approved by ethical committee of Universitas Muhammadiyah Yogyakarta, No.014/EC-EXEM-KEPK FKIK UMY/I/2020.

\section{RESULTS AND DISCUSSION}

Table 1 shows that most of the subject has a role as housewife due to the gender in this research most were female (130 women). As a Labor was second occupies. Most of them were male (in construction area and farming) some of them were working in anything area. Only ten female were in their own mini shop and two men were as pensions. The education level showed that most of the subject was junior high school (65.5\%). They did not have any skill to survive, and only one had a college degree. Some of them had a relative nearby their house. A part of Ambarketawang such as Patukan area is rather the closed area for foreign people. Since 1990 many foreign people were located to Patukan area.

Table 1. Characteristic of occupies and education levels of subjects

\begin{tabular}{cccccc}
\hline Occupies & Number & Frequencies & Education & Number & Frequencies \\
\hline House wife & 75 & $53.40 \%$ & No educated & 5 & $3.20 \%$ \\
Labor & 65 & $34.50 \%$ & Junior High School & 85 & $65.50 \%$ \\
Farming & 5 & $3.20 \%$ & Senior High School & 58 & $27.60 \%$ \\
Retail & 5 & $3.20 \%$ & Diploma & 7 & $1.70 \%$ \\
Pensions & 8 & $5.06 \%$ & College & 3 & $1.70 \%$ \\
& 158 & & & 158 & \\
\hline
\end{tabular}

Low fiber menu and activity of the subject showed in Table 2. Menu with low fiber were 50 percent consumed by female subject. But at male subject only $37.5 \%$. Most of female (58.7\%) had low activity, male with low activity were $37.5 \%$. Most of subject were not smoking. Only one man was did smoking. And none of subject consumed alcohol. Table 2 showed that female elderly has low activity more than 50\%, as female elderly in Patukan. Most of them as house wife and live with their big family, so their need is fulfill by their daughter or others. But some of female elderly had routine activity such as sweeping their large yard, washing the clothes, and look after their grandchildren. The Pearson correlation analyze on Table 3 showed that the significant correlation is between Activity and Systole also Diastole. Based on previous research reported that not practicing physical activity had uncontrolled hypertension [6, 7]. Meanwhile the knowledge on the influence of physical activity on the hypertensive heart remains limited [8]. Although in recent research there was not significance difference on the correlation between education level and systole also diastole but education has significance correlation with occupies. This result in line with 
Degano, et al., 2017 showed that no significant different between education level and incidence of cardiovascular diseases, BMI and physical activity [9] but not with Kiely et al., 2012 reported that higher education is significant with low systolic blood pressure in Boston elderly [10].

Table 2 shows the low fiber food consumed $50 \%$ female and $27.3 \%$ on male. Low of fiber has a risk to defecation problem. On this research, female elderly population has $50 \%$ with low fiber menu. There is not significant different between BMI, systole, diastole and fiber food in Elderly but this must be curious due to chronic of defecation as a risk to the cancer colorectal which is elderly as a risk person. Intakes of vegetable fiber, insoluble fiber, soluble fiber and total fiber showed a trend to reduce the risk of colon cancer $(p<0.05)$ [11]. High intake dietary fiber and whole grains was associated with a reduced risk of colorectal cancer [12]. The protective effect of fiber could be due to various mechanisms. (i) In the large intestine, fiber can increase fecal output, pass stool carcinogens, shorten the stool transit time and reduce carcinogen contact with the large intestinal epithelium. (ii) Fiber can bind bile acids, which produce carcinogens. (iii) Fiber can be fermented by intestinal flora into short chain fatty acids. Butyrate is one of the main short chain fatty acids in the human intestine, which has the ability to inhibit carcinogenesis. (iv) Fiber can reduce hyper-insulin by delaying the starch absorption. Dietary fibers have a beneficial impact on main pathophysiological pathways involved in cardiovascular risk i.e., insulin resistance, renin-angiotensin, and sympathetic nervous systems [13]. As reported, fruit consumption before eating high glycemic carbohydrate reduced blood glucose levels and waist circumference in healthy adults [14]. The obese female worker tends have a significantly lower dietary fiber [15].

Table 2. Quality of activities and low fiber menu

\begin{tabular}{ccccc}
\hline & \multicolumn{2}{c}{ Female } & \multicolumn{2}{c}{ Male } \\
\hline & Yes & No & Yes & No \\
Smoking & $0.0 \%$ & $100.0 \%$ & $9.0 \%$ & $91.0 \%$ \\
Low activity & $58.7 \%$ & $41.3 \%$ & $27.3 \%$ & $72.3 \%$ \\
Low fiber menu & $50.0 \%$ & $50.0 \%$ & $27.3 \%$ & $72.3 \%$ \\
Alcohol consume & $0.0 \%$ & $100.0 \%$ & $0.0 \%$ & $100.0 \%$ \\
\hline
\end{tabular}

Table 3. Characteristic performance of research subjects

\begin{tabular}{lccc}
\hline & Male $(\mathrm{n}=28)$ & Female $(\mathrm{n}=130)$ & T test (Male-Female) \\
\hline Systole $(\mathrm{mmHg})$ & $145.8 \pm 11.9$ & $139.3 \pm 5.1$ & 0.231 \\
Diastole $(\mathrm{mmHg})$ & $83.2 \pm 6.7$ & $81.5 \pm 7.9$ & 0.602 \\
Body weight $(\mathrm{Kg})$ & $60.1 \pm 8.6$ & $53.6 \pm 12.4$ & 0.105 \\
Height $(\mathrm{Cm})$ & $160.2 \pm 2.9$ & $147.3 \pm 5.9$ & 0.000 \\
BMI_Kg/Cm & $14.5 \pm 7.8$ & $24.2 \pm 5.6$ & 0.395 \\
Circumference waist $(\mathrm{Cm})$ & $92.4 \pm 1.3$ & $89.5 \pm 3.2$ & 0.274 \\
Age(years, month) & $67.8 \pm 7.1$ & $67.5 \pm 7.3$ & 0.166 \\
\hline
\end{tabular}

Meanwhile in Table 3 shows that the systole and diastole showed high since the elderly condition, the average trends to hypertension stage 1. Arterial hypertension especially systole hypertension is increasing steadily worldwide, mainly as result of aging of the population and is going one third of world's population on 2025 [16, 17]. Systole hypertension and pulse pressure are better indicator of cardiovascular disease for elderly [16], such as heart failure, stroke, myocardial infarction, and death [17]. In elderly, decreasing of diastole blood pressure determine of height arterial stiffness therefore showing in arterial aging but a little in peripheral resistance. In this case low diastole blood pressure correlated with increasing of systole blood pressure or pulse pressure values and increased cardiovascular diseases [18].

The management of systole hypertension on elderly to lowering hypertension, in example non pharmacologic treatment as lifestyle modification, such as increase physic activity to loss of weight especially for overweight or obese person, consume health diet including decrease in sodium intake along and increase potassium intake (exclude contraindicated), moderation in alcohol intake also stop for all tobacco product [19]. The second part is pharmacologic treatment, which is antihypertensive drug should be start at the minimum dose and gradually be raise depending on the blood pressure response up to the maximum tolerated dose. But if the response is inadequate after reaching maximum dose, then a second drug from another group should be added. Unfortunately, the international guidelines for recommendations about treatment of hypertension in older adults much less clear with large inconsistencies across different guidelines rather than in middle-aged adults [20].

In this study the average of systole on male higher than female. Also diastole little bit higher than female. But BMI in male lower than female. The waist circumference in man higher than female. Overweight and obesity are related to cardio-metabolic risk factors such as high blood pressure, high blood 
glucose level and dyslipidemia [21]. Visceral adiposity index correlated with the concentration of blood pressure, total ccholesterol, uric acid, and glucose values. Visceral adiposity index is able as an indicator in screening for hyperglycemia, dyslipidemia, hyperuricemia, and hypertension also associated cardiovascular risk factors [21].

Table 4 showed the result of correlation analyzing using Pearson correlation between all variables and significantly at 0.01 . Correlation between sex and systole, diastole, age, BMI and waist circumference (WC) had negative mark due to man higher than women but $\mathrm{t}$ test showed there was not significant difference between male and female as shown in Table 4. The significant difference was between BMI and waist circumference but BMI and another variable such as systole, diastole, age, and sex there were not significant. Meanwhile BMI, WC, and a combination of BMI and WC were independently associated with the subsequent development of hypertension in elderly Chinese population [22].

Table 4. Pearson correlation between sex, systole, diastole, age, BMI and waist circumference

\begin{tabular}{|c|c|c|c|c|c|c|}
\hline & & Systole & Diastole & Age & BMI & Waist circ. \\
\hline \multirow[t]{2}{*}{ Sex } & Pearson corr. & -0.1598 & -0.0699 & -0.18432 & -0.1459 & -0.1138 \\
\hline & Sig. (2-tailed) & 0.2307 & 0.6019 & 0.166025 & 0.2743 & 0.3948 \\
\hline \multirow[t]{2}{*}{ Systole } & Pearson corr. & 1 & 0.576 & 0.169359 & -0.0089 & -0.0089 \\
\hline & Sig. (2-tailed) & - & $0.00 * *$ & 0.2037 & 0.9471 & 0.5642 \\
\hline \multirow[t]{2}{*}{ Diastole } & Pearson corr. & - & 1 & 0.0038 & 0.0931 & 0.0107 \\
\hline & Sig. (2-tailed) & - & - & 0.9772 & 0.4868 & 0.9366 \\
\hline \multirow[t]{2}{*}{ Age } & Pearson corr. & - & - & - & -0.0469 & 0.0018 \\
\hline & Sig. (2-tailed) & - & - & - & 0.7263 & 0.9890 \\
\hline \multirow[t]{2}{*}{ BMI } & Pearson corr. & - & - & - & 1 & 0.6583 \\
\hline & Sig. (2-tailed) & - & - & - & - & $0.00 * *$ \\
\hline
\end{tabular}

**risk Correlation is significant at the 0.01 level (2-tailed).

This research found that the elderly in Ambarketawang Gamping Sleman had health problem due to waist circumference and BMI. The average of waist Circumference in male and female were $92.4 \pm 1.3$ and 89.5 \pm 3.2 due to the average of their height were $160.2 \pm 2.9$ and $147.3 \pm 5.9$ each in male and female respectively. These showed that elderly in Ambarketawang Gamping tend to central obesity due the proportional of their body. Though the measuring of fat distribution is necessary to record. Indicators of body fat distribution are associated with cardiovascular disease (CVD) risk factors in the elderly. In old age, the waist and adominal sagital diameter (ASD) are the anthropometric indicators of fat distribution most related to CVD risk factors [5, 23]. Obesity is usually considered a tendency for atherosclerosis cardiovascular disease (ASCVD) but mild obesity or overweight can protect some elderly populations [24, 25]. Waist obesity defined by waist circumference (WC) or waist to height ratio (WHtR), have higher accuracy to reflect the visceral fat and it has been shown to be more strongly associated with CVDs and overall mortality than BMI. Mainly, a WHtR value more than 0.53 was strongly associated with prevalent ASCVD and its risk factors with a higher value for odds ratio than WC and BMI in these elderly Chinese. Meanwhile Visscher reported that measuring waist circumference in never-smokers detect more people who have a higher mortality risk than measuring BMI [26]. Measuring waist circumference may have more potential to detect overweight among elderly men than measuring BMI. Women and man elderly in Padang Indonesia had high dyslipidemia prevalence so that the measuring routinely of blood lipid and anthropometry was necesesary to carry out due to the level of triglyceride (>50\%), ratio of total cholesterol and HDL also central obesity (46\%), had a positive correlation with increasing of cardiovascular diseases 2 [2]. Meanwhile the trend of increasing risk on mortality of Indonesian women with large waist circumference was higher [27]. Wang et al., 2019 also reported that waist circumference is associated with blood pressure China adult population during 1995-2015 [28] also amongst Korean adult with age between 20-80 years old showed that WC is the best predictor of hypertension incidence when evaluate WC, BMI, age, and gender risk factors [29]. WC is a more reliable predictor of Hhypertension than BMI or Body Fat percentage among elderly in Taiwan [30].

\section{CONCLUSION}

Elderly in Ambarketawang had a health risk on the obesity due to high body weight and waist ciscumference but not with blood pressure. Therefore the programme to reduce body weight and to increase the activity necessary to be arranged according to the circumstances and habits of elderly in Ambarketawang. 


\section{REFERENCES}

[1] WHO, World report on Ageing and Health, 2015. [Online], Available https://apps.who.int/iris/bitstream/handle/10665/186463/9789240694811_eng.pdf;jsessionid=3F19AA8E495C84E B415EFDE63F70867E? sequence

[2] Data and Information Center: Elderly. Elderly analyze and situation. Ministry of Health of The Republic Indonesia. Jakarta, pp. 1-8, 2014

[3] Statistics Center Bureau. Life Expectancy at Birth Based on Province year 2010-2017. 2019. [Online]. Available: https://www.bps.go.id/dynamictable/2018/04/16/1298/angka-harapan-hidup-saat-lahir-menurut-provinsi-2010-2017.html

[4] Data and Information Center: Elderly Infodatin Hipertensi. Hipertensi. Kementrian Kesehatan Republik Indonesia. Jakarta, pp. 1-8, 2014

[5] Turcato E, Bosello O, Di Francesco V, Harris TB, Zoico E, Bissoli L, Fracassi E., and Zamboni M., "Waist circumference and waist sagittal diameter as surrogates of body fat distribution in the elderly: their relation with cardiovascular risk factors," International Journal of Obesity, vol. 24, no. 8, pp. 1005-1010, 2000.

[6] Hegde SM and Solomon SD., "Influence of Physical Activity on Hypertension and Cardiac Structure and Function," Current Hypertension Reports Journal, vol. 17, no, 10, p. 77, October 2015.

[7] Diaz KM., Shimbo D., "Physical Activity and the Prevention of Hypertension," Current Hypertension Reports Journal, vol. 15, no. 6, pp. 659-668, 2013.

[8] Song Y., Liu M., Yang FG, Cui LH, Lu XY., Chen C., "Dietary Fiber and the Risk of Colorectal Cancer: a Case Control Study," Asian Pacific Journal Cancer Prevention, vol. 16, no. 9, pp. 3747-3752, 2015.

[9] Dégano IR, Marrugat J., et al., "The association between education and cardiovascular disease incidence is mediated by hypertension, diabetes, and body mass index," Scientific Reports, vol. 7, no.1, pp. 12370, 2017.

[10] Kielya DK, Alden L., Grossa AL, Kima DH and Lewis A., Lipsitza A., "The association of educational attainment and SBP among older community-living adults: the Maintenance of Balance, Independent Living, Intellect and Zest in the Elderly (MOBILIZE) Boston Study," Journal of Hypertension, vol. 30, no. 8, pp. 1518-1525, August, 2012.

[11] Aune D, Chan DSM , Lau Rosa, Viera R, Wood DCG, Kampman E, Norat T., "Dietery Fibre, whole grains, and Risk of Colorectal Cancer: Review, and dose Response meta-analysis of prospective studies," BMJ, vol. 343, pp. 1-20, 2011. https://doi.org/10.1136/bmj.d6617.

[12] Bozzetto L, Costabile G, Della Pepa G, Ciciola P, Vetrani C, Vitale M, Rivellese AA and Annuzz G., "Dietary Fibre as a Unifying Remedy for the Whole Spectrum of Obesity-Associated Cardiovascular Risk," Nutrients, vol. 10, no. 7, pp. 943, 2018. doi:10.3390/nu10070943

[13] Nagoro DS, Tamtomo DG, Indarto D., "A randomized control trial related to meal order of fruit, vegetable and high glycaemic carbohydrate in healthy adults and its effects on blood glucose levels and waist circumference," Bali Medical Journal, vol. 8, no. 1, pp. 247-254, 2019.

[14] Hadrévi J., Søgaard K., and Christensen JR., "Dietary Fiber Intake among Normal-Weight and Overweight Female Health Care Workers: An Exploratory Nested Case-Control Study within FINALE-Health," Hindawi Journal of Nutrition and Metabolism, vol. 2017, pp. 1-7, 2017. https://doi.org/10.1155/2017/1096015

[15] Alsairafi M., Alshamali K., Al-rashed A., "Effect of Physical Activity on Controlling Blood Pressure among Hypertensive Patients from Mishref Area of Kuwai," European Journal of General Medicine, vol. 7, no. 4, pp. 377-384, 2010.

[16] Benetos A., Petrovic M., Strandberg T., "Hypertension Management in Older and Frail Older Patients," Circulation Research, vol. 124, no. 7, pp. 1045-1060, 2019. https://doi.org/10.1161/CIRCRESAHA.118.313236

[17] Oliveros E., Patel, H., Kyung S., Fugar S., Goldberg A., Madan N., Williams KA., "Hypertension in older adults: Assessment, management, and challenges," Clinical Cardiology, vol. 43, pp. 99-107, 2020. https://doi.org/10.1002/clc.23303

[18] Currie G., Delles C., "Blood pressure targets in the elderly," Journal of Hypertension, vol. 36, no. 2, pp. 234-236, 2018.

[19] Davis LL, "Hypertension: How Low to Go When Treating Older Adults," The Journal for Nurse Practitioners$J N P$, vol. 15, no. 1, pp. 1-6, 2019.

[20] Anker D., Santos-Eggimann B., Santschi V., Del Giovane C., Wolfson C., Streit S., Rodondi N., and Chiolero A., "Screening and treatment of hypertension in older adults: less is more?," Public Health Reviews, vol. 39, no. 26, pp. 1-16, 2018. https://doi.org/10.1186/s40985-018-0101-z

[21] Czeczelewskia M., Czeczelewskib J., Czeczelewskac E., Galczak-Kondraciukb A., "Association of body composition indexes with cardio-metabolic risk factors," Obesity Medicine, vol. 17, pp. 1-5, 2020. https://doi.org/10.1016/j.obmed.2019.100171

[22] Momin M., Fan F., Li J., Jia J., Zhang L., Zhang Y., Huo Y, "Joint Effects of Body Mass Index and Waist Circumference on the Incidence of Hypertension in a Community-Based Chinese Population," Obes Facts., vol.13, no. 2, pp. 245-255, 2020.

[23] Seidell JC., and Visscher TLS., "Body weight and weight change and their health implications for the elderly," European Journal of Clinical Nutrition, vol. 54, no. Suppl. 3, pp. S33-S39, 2000. https://doi.org/10.1038/sj.ejen.1601023 
[24] Fan H, Li X, Zheng L, et al., "Waist obesity is strongly associated with Cardiovascular Disease and its Risk Factors in Elderly and very Elderly Community-dwelling Chinese," Scientific Reports, vol. 6, pp. 21521, 2015. doi:10.1038/srep21521

[25] Visscher TLS, Seidell JC, Molarius A, Kuip DVD, Hofman A and Witteman JCM., "A comparison of body mass index, waist-hip ratio and waist circumference as predictors of all-cause mortality among the elderly: the Rotterdam study," International Journal of Obesity, vol. 25, no. 11, pp. 1730-1735, 2001.

[26] Perissinotto E., Pisent C., Sergi G., Grigoletto F., and Enzi G., "Anthropometric measurements in the elderly: age and gender differences," British Journal of Nutrition, vol. 87, no. 2, pp. 177-186, 2002.

[27] Pujilestari CU., Nyström L., Norberg M., and Ng N., "Waist Circumference and All-Cause Mortality among Older Adults in Rural Indonesia," International Jounal of Environmentl Reasearch and Public, vol. 16, no. 1, pp. 116, 2019. doi:10.3390/ijerph16010116

[28] Wang Y., Howard AG., Adair LS., Wang H, Avery CL, and Gordon-Larsen P., "Waist Circumference Change is Associated with Blood Pressure Change Independent of BMI Change," Obesity Journal, vol. 28, no. 1, pp. 146-153, 2019. doi:10.1002/oby.22638

[29] So Hyun Park SH And Kim SG, "Comparison of Hypertension Prediction Analysis Using Waist Measurement and Body Mass Index by Age Group,” Osong Public Health and Research Perspective, vol. 9, no. 2, pp. 45-49, 2018.

[30] Lin YA., Chen YJ., Tsao YC.,Yeh WC., Li WC.,1,5 Tzeng IS., Chen JY, "Relationship between obesity indices and hypertension among middle-aged and elderly populations in Taiwan: a community-based, cross-sectional study,” BMJ Open, vol. 9, no. 10, pp. 1-8, 2019. doi:10.1136/ bmjopen-2019-031660 